\title{
Mineração
}

\section{Políticas ambientais nas empresas brasileiras: análise de conteúdo}

\author{
José Alexandre Gurgel do Amaral \\ Engenheiro de Minas e Metalurgia \\ Mestrando no Mestrado Profissional em Sistemas de Gestão - LATEC/UFF \\ E-mail:flori@uninet.com.br \\ Angela Maria Abreu de Barros \\ D.Sc., Professor Adjunto IV, Departamento de Físico-Química, UFF \\ E-mail:amabreu@uol.com.br
}

\section{Resumo}

O trabalho descreve a análise de conteúdo realizada em 136 Políticas Ambientais-PAs de empresas operando no Brasil, certificadas segundo os requisitos da NBR ISO 14001:1996. As empresas foram identificadas nas "listagens de empresas certificadas", segundo publicações na Revista Meio Ambiente Industrial-Edição Especial, de maio/junho de 1999 e julho/agosto de 2001. A documentação referente às PAs foi obtida por solicitação direta às empresas via $e$-mail e/ou postal, ou por acesso aos sites postos à disposição das partes interessadas.

O conteúdo das PAs foi analisado sob o ponto de vista da manifestação explícita no texto da consideração do critério econômico-financeiro no processo de tomada de decisão gerencial, em face de outras manifestações explicitando a postura da empresa em relação ao atendimento dos requisitos legais e à oferta de benefícios para a sociedade.

Constatou-se a inadequação das ferramentas postas à disposição das partes interessadas e, no principal, a percepção alcançada é que a comunicação externa é ineficiente e ineficaz. Verificou-se que $73 \%$ das PAs não manifestam preocupação econômico-financeira na condução da gestão ambiental. Adicionalmente, verificou-se que $58 \%$ das PAs pertencem às categorias das que se comprometem voluntariamente a um desempenho ambiental superior ao mínimo compulsório, não submetendo as ações a qualquer análise custo-benefício de natureza econômico-financeira. Finalmente, a partir da análise dos resultados, pode-se inferir que existe uma diferença entre o desempenho ambiental contido nas manifestações escritas (a "teoria") e as práticas gerenciais vivenciadas e descritas no trabalho.

Palavras-chave: Análise de conteúdo, política ambiental, contabilidade gerencial ambiental e desempenho ambiental.

\begin{abstract}
The article analyses the content of 136 Environmental Policies - EPs of companies operating in Brazil and which have been certified in accordance to the requisites of NBR ISO 14001:1996. These companies were identified in the "certified companies listing" in the magazine Revista Meio Ambiente Industrial - Edição Especial, May/June 1999 and July/August 2001 issues. The EPs actual texts were obtained through direct requests made to the companies, via e-mail and/or postmail, and, also, captured from the companies' websites when at the disposal of interested parties.
\end{abstract}

The content of the EPs was analysed from the point of view of whether or not there was an explicit indication in the EP text that an economical and financial criterium has been employed in the management decision process, in face of the other expressions expliciting the companies' stand in relation to meeting legal requisites and to offering benefits to society.

It has been verified that the tools provided to the interested parties are inadequate and, mainly, that company outside communication is inefficient and ineffective. It has been found that $73 \%$ of the EPs do not reveal an environmental management concern regarding economical and financial aspects. Furthermore, it has been found that $58 \%$ of the EPs are included in the category of those that voluntarily commit to an environmental performance which is beyond the compulsory minimum required, however they do not submit their actions to any cost and benefit analysis of an economical and financial nature. Finally, the results found permit one to infer that there is a difference between the environmental performance expressed in the writings (the "theory") and the management practices experienced and described at work.

Keywords: Content analysis, environmental policy, environmental management accounting, environmental performance.

Artigo recebido em 24/06/2002 e aprovado em 20/08/2002 . 


\section{Introdução}

Esse artigo descreve a análise de conteúdo realizada em cento e trinta e seis Políticas Ambientais-PAs de empresas operando no Brasil, certificadas segundo os requisitos da NBR ISO 14001:1996.

É sabido que se constitui em um requisito da norma referenciada a explicitação no texto da PA apenas do “... comprometimento com o atendimento à legislação e normas ambientais aplicáveis ..." (o grifo é nosso) (item \#4.2.cparte). Tal como posto, senso estrito, pode-se interpretar a não necessidade do atendimento e que, em tese, poderiam vir a ser certificadas empresas que não estivessem atendendo aos requisitos vigentes da legislação aplicável aos seus objetivos e aos seus produtos \& atividades. Isto conduziria a uma situação absurda, ainda que se considere apenas o objetivo da implementação de tais normas.

Objetivando unificar os entendimentos, em julho de 2001, o CB-38, Comitê Brasileiro de Gestão da ABNT Associação Brasileira de Normas Técnicas, emitiu um documento no qual estabelece que "o comprometimento do atendimento à legislação implica que a empresa deve estar atendendo todos os requisitos legais aplicáveis". Assim, considerados o requisito normativo e a sua interpretação unificante, fica definido para as empresas um patamar mínimo de desempenho ambiental, com caráter de cumprimento compulsório e correspondente ao atendimento dos requisitos da totalidade da legislação aplicável e vigente.

Complementarmente, a norma referenciada contém o requisito (item \#4.2.b) que especifica a explicitação no texto da PA do comprometimento com a melhoria contínua do desempenho, assim como o de que a PA forneça a estrutura para a fixação e revisão dos objetivos e metas ambientais (item \#4.2.d). Nesse caso, fica individualizada a abordagem estratégica para a gestão do desempenho ambiental da empresa, que tem o caráter não-compulsório sob o ponto de vista do administrador ambiental público, o que impli- ca, no âmbito da gestão da empresa, a necessidade da implantação e operacionalização de um mecanismo adequado para seleção de alternativas, tendo-se como base métodos de análise custo-benefício. Ora, em ambiente de negócios, é lícito supor que tal mecanismo deverá incluir, em conjunto com outros, algum critério de avaliação segundo aspectos econômico-financeiros.

Diante deste cenário geral, o presente artigo pretende contribuir para a avaliação da resposta para a seguinte questão:

"As empresas brasileiras já incorporaram ao modelo de gestão a contabilidade gerencial ambiental ?"

Para isso estamos nos valendo do método de pesquisa da "análise de conteúdo", realizada sobre Políticas Ambientais (PAs) de empresas que tenham sido certificadas segundo os requisitos especificados na ISO 14001.

O objetivo dessa análise é fazer uma verificação qualitativa da manifestação explícita no texto da PA sobre a consideração do critério econômico-financeiro no processo de tomada de decisão gerencial. Essa preocupação ocorre, principalmente, em face de outras manifestações explicitadas no texto, relacionadas com a assunção de posturas pró-ativas frente a determinadas situações, e/ou relacionadas com a adoção voluntária de princípios de gestão e rotas tecnológicas mais avançadas e/ou relacionadas com a fixação de objetivos e metas ambientais desafiantes.

\section{Metodologia 2.1 Seleção e coleta das PAs}

Adotou-se o critério da seleção aleatória,independente da natureza/setor de atividade ou localização da empresa no território nacional brasileiro. O prérequisito é que a empresa tenha sido certificada em conformidade com os requisitos da norma NBR ISO 14001.

As empresas foram identificadas nas "listagens de empresas certificadas", segundo publicações na Revista Meio Ambiente Industrial-Edição Especial, de maio/junho de 1999 e julho/agosto de 2001, de acordo com as referências bibliográficas.

Devido a razões circunstanciais de disponibilidade de recursos, as PAs foram coletadas em dois momentos do tempo, sem que, entretanto, fosse introduzido algum viés na amostra obtida. Assim, em julho/setembro de 1999, foi realizada uma primeira campanha tendo sido obtidas 51PAs. A segunda campanha foi realizada entre abril/maio de 2002, obtendo-se 85 exemplares de PAs.

Na primeira campanha, a abordagem da listagem se deu segundo a ordem alfabética de nomes de empresas, através do envio de cartas solicitando a cópia da PA. Tendo em vista o baixo índice de respostas obtidas, foram tentados contatos diretos por telefone, obtendo-se, mais uma vez, um baixo índice de respostas positivas. Finalmente, por indicação de algumas das empresas contatadas por telefone, obteve-se o endereço eletrônico, sendo feita a leitura e captura de PAs disponíveis em sites da Internet. Após a interrupção da campanha, 51 exemplares de PAs tinham sido coletados em um universo de cerca de 100 empresas pesquisadas.

A execução da segunda campanha iniciou-se pela tentativa da coleta indireta, via Organizações Certificadoras (OCs). Nesse sentido, foram contatadas por $e$-mail seis OCs, das quais apenas duas responderam, assim mesmo negativamente, por motivos que serão comentados e analisados na seção de resultados. Diante da impossibilidade da coleta indireta, retomou-se a metodologia adotada anteriormente, utilizando os endereços dos sites. Nos casos em que os sites não explicitavam as PAs, foram tentados os instrumentos do tipo "fale conosco". Para as tentativas "sem sucesso", quando indicado o endereço no site, foi tentado o contato por telefone e/ou por telefax. No total foram tentados 194 contatos, dos quais resultaram 85 exemplares de PAs. A campanha foi interrompida ao ser alcançada a quantidade total (primeira e segunda campanhas) de 136 exemplares em um universo de cerca de 330 empresas definidas para a pesquisa. 


\subsection{Conteúdo da PA}

A primeira consideração que se faz é relativa à manifestação explícita na $\mathrm{PA}$ da inclusão do critério econômico-financeiro no processo gerencial de tomada de decisão. Nessa perspectiva, adotouse uma abordagem bastante flexível, considerando-se, além da PA propriamente dita, outros documentos estratégicos, desde que disponíveis para o público. De outra parte, alargando ainda mais a faixa de respostas consideradas positivas à manifestação econômico-financei$\mathrm{ra}$, aceitaram-se indicações indiretas e não-explícitas daquela manifestação. Em seguida, são indicados dois trechos de textos de PAs, considerados típicos, selecionados para exemplificar a aplicação do critério adotado. São eles:

-... eliminar os impactos ambientais, quando técnica é economicamente viável.

-... acolhendo, sempre que possível, aperfeiçoamentos adicionais (observação: o grifo é para chamar a atenção do leitor sobre a flexibilidade na aplicação do critério; neste caso, a expressão "sempre que possível" foi tomada na acepção de "viabilidade técnica e econômica", considerada a lógica empresarial).

Considerado o aspecto da manifestação da "preocupação econômico-financeira", as PAs foram grupadas sob as subcategorias "sim" e "não".

O segundo aspecto analisado foi quanto à manifestação (na PA) da abordagem para o cumprimento dos requisitos legais, tendo sido identificadas duas vertentes dominantes: a do grupo das PAs que apenas explicitam o cumprimento da legislação ambiental vigente e aplicável e a vertente do grupo que se impõe a um desempenho que vai além do especificado na legislação.

O último aspecto analisado diz respeito à explicitação na $\mathrm{PA}$, ou não, do compromisso de tomada de atitude ou de desempenho que gere benefícios para o meio ambiente e para as partes interessadas. Entre aquelas PAs que contêm tal explicitação, elas são estruturas, em geral, através da observação dos códigos ou princípios de conduta e do compor- tamento empresarial; e/ou através da definição da prioridade da função gerencial ambiental, incorporando tal prioridade às atividades e aos processos decisórios da empresa; e/ou, finalmente, através da extensão às partes interessadas (PIs) externas os programas e os projetos de educação e de promoção da cidadania. Considerando o aspecto da manifestação de "oferta de outros benefícios", as PAs foram grupadas sob as categorias "sim" e "não".

Considerados os três aspectos adotados para a análise dos seus conteúdos, as PAs foram categorizadas segundo as subcategorias nomeadas nos Quadros \#01 e \#02, incluídos na seção 3.2 , seguinte.

Adicionalmente, as PAs foram classificadas quanto à característica do conteúdo abordado em conjunto com os aspectos da gestão ambiental, da qualidade, da saúde e da segurança do trabalhador ou quanto à referência apenas à questão ambiental.

\section{Resultados}

\subsection{Etapa da coleta das PAs}

Preliminarmente devem ser anotadas algumas observações relacionadas com a divulgação e comunicação de PAs. Com efeito, é da própria lógica do sistema, que se assenta na credibilidade pública das certificações, que sejam dadas a mais ampla divulgação e as facilidades para a compreensão da PA e do sistema de gestão e outros seus elementos. Prescrição esta que a norma NBR ISO 14001 incorpora segundo diversos requisitos. Em relação a PA, o seu item \#4.2 especifica que ela "seja documentada, implementada, mantida e comunicada a todos os empregados" e que "esteja disponível para o público".

A segunda campanha de coleta considerou a possibilidade de receber exemplares das PAs diretamente das Organizações Certificadoras (OCs). Para tanto, foi solicitada ao INMETRO e por ele fornecida uma listagem de OCs indicando seus endereços eletrônicos e postais. Ao final, somente duas OCs responderam à solicitação. As respostas são coincidentes e correspondem à informação de que não é permitido divulgar informações "confidenciais" sobre os clientes, sob pena de perda da licença de Organização Certificadora.

São identificados dois fatos relevantes para a caracterização do ambiente envolvendo e determinando a praxis da certificação ambiental de empresas operando no Brasil. O primeiro diz respeito ao fato de que cinco, entre sete, OCs contatadas não deram resposta a uma solicitação de uma parte interessada, ainda que estivessem "proibidas" de atender o pedido. $\mathrm{O}$ segundo aspecto diz respeito à proibição propriamente dita, que conduz a uma situação insólita, considerados o objetivo do sistema de gestão ambiental e de seus elementos componentes e, sobretudo, dos interesses das empresas certificadas.

Do total de 350 empresas integrantes da listagem publicada em 2001 (Revista Meio Ambiente Industrial), foram selecionadas para contato 337 empresas. Destas, foi tentado contato com 257 empresas, resultando, ao final, a seguinte situação:

- Em 81 empresas não se obteveram sucesso em estabelecer o contato (32\%).

- Em 40 empresas obteveram-se o sucesso em estabelecer o contato, porém não houve resposta (16\%).

- Em 85 empresas obteveram-se contato e resposta, obtendo-se exemplares de PAs (33\%).

- Em 51 empresas obteveram-se as PAs na primeira campanha (20\%).

O primeiro aspecto que cabe destacar diz respeito ao modo de comunicação virtual, que, na prática, ainda é "inamistoso". Foram identificadas diversas razões de insucesso para estabelecer o contato, em relação ao site, por exemplo: não é encontrado, ou não abre; não contém a PA; não indica nenhuma outra alternativa para contato; os formulários contidos nele são recusados; os e-mail remetidos para os endereços indicados no site são recusados; o endereço indicado no site não é exclusivo. A prática da tentativa de contato por telefone não é diferente. 
Uma vez estabelecido o contato virtual, a comunicação é dificil e demorada, não disponibilizando a PA. Na alternativa de contato estabelecido via telefone não foi raro não se obterem respostas e, em muitos contatos, a transferência da responsabilidade da informação era passada por vários departamentos/setores, sem resultado efetivo.

Em resumo, a percepção alcançada é que as empresas, por facilidade e menor custo, passaram a responsabilidade da prestação das informações para os mecanismos e canais de divulgação virtuais, mas estes são ineficazes. Também, constatou-se que o canal de diálogo ainda tem de ser aperfeiçoado e incorporado às culturas das empresas.

\subsection{Conteúdo das PAs}

Quanto ao critério de abordarem outros aspectos além do ambiental, a amostra evidencia que $60 \%$ pertence a classe das políticas "não integradas" e $40 \%$, a classe das "integradas". Quanto a estas, a distribuição é uniforme.

Foram encontradas duas PAs que abordam outros aspectos diversos daqueles identificados. Uma delas manifesta compromissos com a manutenção e promoção da cultura tradicional original do local onde a empresa desenvolve suas atividades e a outra atende aos requisitos de norma de responsabilidade social. De outra parte, embora não tenha significado estatístico, deseja-se chamar a atenção para o fato de que PAs de duas empresas estão disponíveis no site em lingua inglesa.

Retomando as categorias identificadas na seção 2.2 , constata-se que $27 \%$ das PAs manifestam, de alguma forma, uma preocupação de natureza econômico-financeira na condução da gestão ambiental e que $73 \%$ não manifestam essa preocupação. Entre as que não manifestam a preocupação, $80 \%$ delas (correspondente a $58 \%$ do total das cento e trinta seis PAs) pertencem às categorias das que se comprometeram com um desempenho superior ao mínimo. Esse agrupamento corresponde ao de maior risco para a sustentabilidade da empresa, pois os "comprometimentos", teoricamente, não são submetidos a qualquer análise custo-benefício. O Quadro 01 mostra os resultados para as PAs categorizadas como "aspectos econômicos-não".

Adicionalmente, os resultados indicam (não mostrado no Quadro 01), que, das 99 PAs da categoria, 70 delas correspondem a políticas “não-integradas". As "integradas" mantêm a distribuição uniforme já nomeada anteriormente.

As PAs categorizadas como "aspectos econômicos-sim" apresentaram os resultados mostrados no Quadro 02.

Como se vê, a subcategoria do "menor risco" para a sustentabilidade da empresa, consistindo na manifestação do comprometimento de atendimento estrito dos requisitos legais e da não oferta de benefícios extraordinários, ao mesmo tempo que submete os instrumentos e mecanismos da gestão ambiental à análise custo-benefício, corresponde ao menor valor percentual, alcançando apenas $14 \%$ das PAs da categoria (equiva-

Quadro 01 - PAs - categoria aspectos econômicos "não".

PAs categoria aspectos econômicos "não"

\begin{tabular}{|c|c|c|c|c|}
\hline \multirow{2}{*}{\multicolumn{2}{|c|}{ Subcategorias }} & \multicolumn{3}{|c|}{ Quantitativos } \\
\hline & & \multirow{2}{*}{$\begin{array}{c}\text { Und. } \\
33\end{array}$} & \multicolumn{2}{|c|}{ Pct. } \\
\hline 1.1 & Legislação "mais" / benefícios "sim" & & 42 & 33 \\
\hline 1.2 & Legislação "mínimo" / benefícios "sim" & 41 & 52 & 42 \\
\hline 1.3 & Legislação "mais" / benefícios "não" & 05 & 6 & 5 \\
\hline 1.0 & Sub Total $(1.1+1.2+1.3)$ & 79 & 100 & 80 \\
\hline 2.0 & Legislação "mínimo" / benefícios "não" & 20 & - & 20 \\
\hline 3.0 & Total $(1.0+2.0)$ & 99 & - & 100 \\
\hline
\end{tabular}

Quadro 02 - PAs - categoria aspectos econômicos "sim".

PAs - categoria aspectos econômicos "sim"

\begin{tabular}{|c|c|c|c|c|}
\hline \multirow{2}{*}{\multicolumn{2}{|c|}{ Subcategorias }} & \multicolumn{3}{|c|}{ Quantitativos } \\
\hline & & \multirow{2}{*}{$\frac{\text { Und. }}{19}$} & \multicolumn{2}{|c|}{ Pct. } \\
\hline 1.1 & Legislação "mais" / benefícios "sim" & & 59 & 51 \\
\hline 1.2 & Legislação "mínimo" / benefícios "sim" & 13 & 41 & 35 \\
\hline 1.3 & Legislação "mais" / benefícios "não" & zero & - & - \\
\hline 1.0 & Sub Total $(1.1+1.2+1.3)$ & 32 & 100 & 86 \\
\hline 2.0 & Legislação "mínimo" / benefícios "não" & 5 & - & 14 \\
\hline 3.0 & Total $(1.0+2.0)$ & 37 & - & 100 \\
\hline
\end{tabular}


- Constatou-se que os mecanismos e as ferramentas de comunicação da gestão ambiental das empresas (certificadas) postos à disposição dos usuários - partes interessadas - são ineficientes e ineficazes, assim como constatou-se a capacitação inadequada do pessoal de atendimento às solicitações dessas partes interessadas.

- Constatou-se que parcela significativa das empresas (certificadas) não reconheceram a demanda de uma parte interessada.

- Constatou-se que a grande maioria das empresas (certificadas) não manifestou que a ferramenta da análise custobenefício estivesse incorporada às práticas de gestão dos seus aspectos ambientais, ao mesmo tempo que explicita para o público - partes interessadas - comprometimentos com desempenhos e benefícios, que, sem o filtro da viabilidade financeira, poderão vir a comprometer suas sustentabilidades econômicas.

- Finalmente, a consideração dos aspectos constatados pela realização da pesquisa, explicitados nos subitens de \#4.1 até \#4.5 anteriores, em conjunto com o reconhecimento do fato de que a lógica e a prática empresarial não dispensam a utilização de alguns dos instrumentos de análise custo-benefício nos processos de tomada de decisão gerencial (principalmente, se relacionados com decisão de investimentos de capital) autorizam a inferência de que existe uma diferença entre o desempenho ambiental contido nas manifestações escritas (a "teoria") e as práticas gerenciais vivenciadas e aqui descritas.

\section{Referências}

\section{bibliográficas}

REVISTA Meio Ambiente Industrial. As Primeiras 100 Empresas Certificadas em Conformidade com a ISO 14001. Edição Especial, Ano IV, Edição 19, n. 18, p. 217. 1999.

REVISTA Meio Ambiente Industrial. O Brasil atinge a Marca das 350 empresas certificadas em Conformidade com a ISO 14001. Edição Especial, Ano VI, Edição 32 , n. 31 , p. 185.2001

\section{Descubra as muitas informações da: Geologia, Mineração,}

Metalurgia \& Materiais e Engenharia Civil.
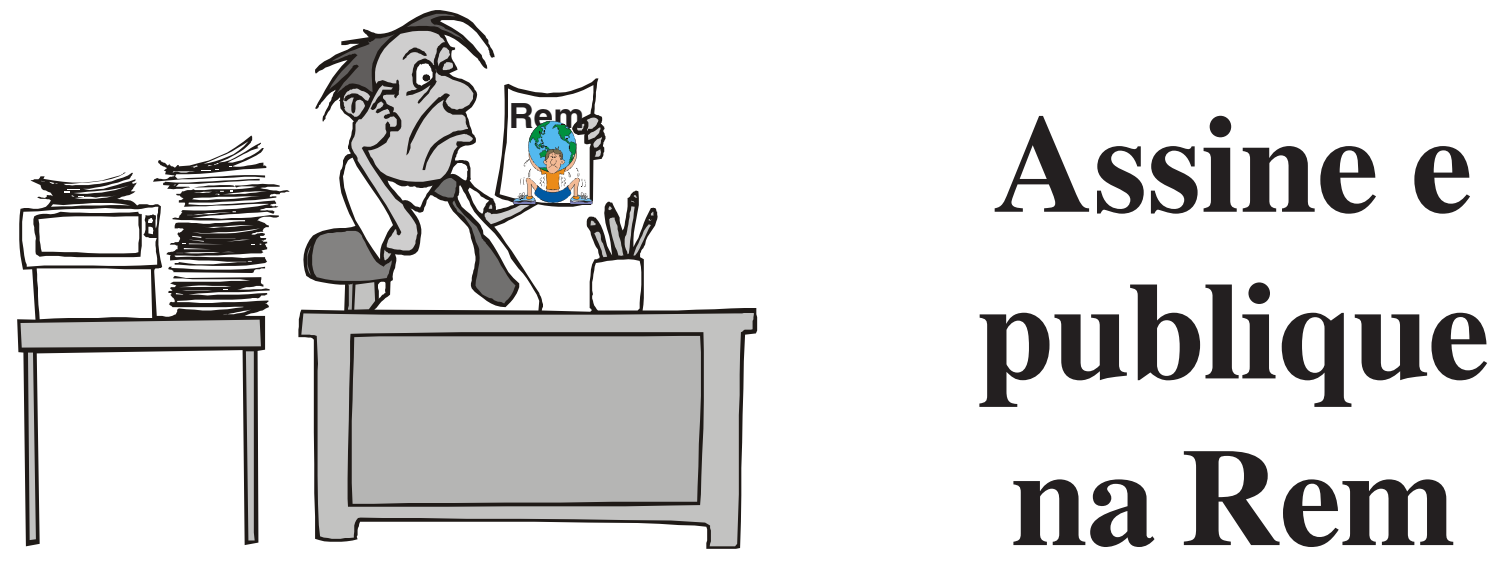

Fone/Fax: (31) 3551- 4730 - E-mail: remjorio@ouropreto.feop.com.br 